\title{
Characterizing Wetland Inundation and Vegetation Dynamics in the Arctic Coastal Plain Using Recent Satellite Data and Field Photos
}

\author{
Zhenhua Zou ${ }^{1, *}$, Ben DeVries ${ }^{1,2}$, Chengquan Huang ${ }^{1}$, Megan W. Lang ${ }^{3}$, Sydney Thielke ${ }^{4}$, Greg W. McCarty ${ }^{5}$, \\ Andrew G. Robertson ${ }^{6}$, Jeff Knopf ${ }^{6}$, Aaron F. Wells ${ }^{7}$, Matthew J. Macander 8 (D) and Ling Du ${ }^{5,9}$
}

Citation: Zou, Z.; DeVries, B.; Huang, C.; Lang, M.W.; Thielke, S.; McCarty, G.W.; Robertson, A.G.; Knopf, J.; Wells, A.F.; Macander, M.J.; et al. Characterizing Wetland Inundation and Vegetation Dynamics in the Arctic Coastal Plain Using Recent Satellite Data and Field Photos. Remote Sens. 2021, 13, 1492. https://doi.org/10.3390/rs13081492

Academic Editor:

Nikos Papadopoulos

Received: 26 March 2021

Accepted: 12 April 2021

Published: 13 April 2021

Publisher's Note: MDPI stays neutral with regard to jurisdictional claims in published maps and institutional affiliations.

Copyright: (c) 2021 by the authors. Licensee MDPI, Basel, Switzerland. This article is an open access article distributed under the terms and conditions of the Creative Commons Attribution (CC BY) license (https:/ / creativecommons.org/licenses/by/ $4.0 /)$.
1 Department of Geographical Sciences, University of Maryland, College Park, MD 20742, USA; bdv@uoguelph.ca (B.D.); cqhuang@umd.edu (C.H.)

2 Department of Geography, Environment and Geomatics, University of Guelph, Guelph, ON N1G2W1, Canada

3 U.S. Fish and Wildlife Service, National Wetlands Inventory, Falls Church, VA 22041, USA; megan_lang@fws.gov

4 U.S. Fish and Wildlife Service, Region 7, Anchorage, AK 99503, USA; sydney_thielke@fws.gov

5 Hydrology and Remote Sensing Laboratory, USDA-ARS, Beltsville, MD 20705, USA; greg.mccarty@usda.gov (G.W.M.); lingdu@umd.edu (L.D.)

6 GeoSpatial Services, Saint Mary's University of Minnesota, Winona, MN 55987, USA; AROBERTS@smumn.edu (A.G.R.); jknopf@smumn.edu (J.K.)

7 ABR, Inc., Anchorage, AK 99524, USA; awells@abrinc.com

8 ABR, Inc., Fairbanks, AK 99709, USA; mmacander@abrinc.com

9 Department of Environmental Science \& Technology, University of Maryland, College Park, MD 20742, USA

* Correspondence: zhzou@umd.edu; Tel.: +1-405-343-7335

Abstract: Arctic wetlands play a critical role in the global carbon cycle and are experiencing disproportionate impacts from climate change. Even though Alaska hosts $65 \%$ of U.S. wetlands, less than half of the wetlands in Alaska have been mapped by the U.S. Fish and Wildlife Service National Wetlands Inventory (NWI) or other high-resolution wetlands protocols. The availability of time series satellite data and the development of machine learning algorithms have enabled the characterization of Arctic wetland inundation dynamics and vegetation types with limited ground data input. In this study, we built a semi-automatic process to generate sub-pixel water fraction (SWF) maps across the Coastal Plain of the Arctic National Wildlife Refuge (ANWR) in Alaska using random forest regression and 139 Sentinel-2 images taken in ice-free seasons from 2016 to 2019. With this, we characterized the seasonal dynamics of wetland inundation and explored their potential usage in determining NWI water regimes. The highest levels of surface water expression were detected in June, resulting from seasonal active layer thaw and snowmelt. Inundation was most variable in riverbeds, lake and pond margins, and depressional wetlands, where water levels fluctuate substantially between dry and wet seasons. NWI water regimes that indicate frequent inundation, such as permanently flooded wetlands, had high SWF values (SWF $\geq 90 \%$ ), while those with infrequent inundation, such as temporarily flooded wetlands, had low SWF values (SWF < 10\%). Vegetation types were also classified through the synergistic use of a vegetation index, water regimes, synthetic-aperture radar (SAR) data, topographic data, and a random forest classifier. The random forest classification algorithms demonstrated good performance in classifying Arctic wetland vegetation types, with an overall accuracy of 0.87. Compared with NWI data produced in the 1980s, scrub-shrub wetlands appear to have increased from 91 to $258 \mathrm{~km}^{2}$ over the last three decades, which is the largest percentage change $(182 \%)$ among all vegetation types. However, additional field data are needed to confirm this shift in vegetation type. This study demonstrates the potential of using time series satellite data and machine learning algorithms in characterizing inundation dynamics and vegetation types of Arctic wetlands. This approach could aid in the creation and maintenance of wetland inventories, including the NWI, in Arctic regions and enable an improved understanding of long-term wetland dynamics. 
Keywords: wetland; inundation; vegetation; sentinel; arctic; ANWR; NWI

\section{Introduction}

Wetlands serve an important role in water purification, water storage, flood mitigation, shoreline protection, and carbon and nutrient cycling [1]. Wetlands are also considered the most biologically diverse of the ecosystems, supporting a wide range of plant and animal species [2]. Climate models generally project the greatest warming at northern high latitudes, which would greatly impact Arctic wetlands in terms of loss of snowpack, and increased evaporation, and thawing of permafrost [3]. The thawing of permafrost could potentially lead to massive greenhouse gas emissions that could further intensify global warming [4]. Likely in part due to climate change, shrub expansion and surface water change have also been observed in the Alaska Arctic wetlands [5]. Despite documentation of Arctic wetland changes, the extent and nature of these changes are still highly uncertain.

The National Wetlands Inventory (NWI) geospatial dataset, produced by the U.S. Fish and Wildlife Service (FWS), is a dataset available to the public that provides detailed information on the abundance, characteristics, history, and extent of U.S. wetlands [6]. Alaska hosts $65 \%$ of the U.S. wetlands [7]. However, more than half of Alaska has no NWI wetland maps, in contrast to complete coverage in the contiguous United States (CONUS). The current approach for producing NWI geospatial data includes manual delineation of wetland boundaries based on aerial or satellite images (e.g., SPOT- Satellite Pour l'Observation de la Terre images) acquired at a single date and subsequent wetland classification based on the image, field sampling data, ancillary data, and expert knowledge [8]. Detailed knowledge of surface inundation and vegetation types is critical to determining wetland type [8]. However, such information is seldom available for much of Alaska because acquiring field data and observations is difficult there. Thus, information on inundation dynamics and vegetation type derived from time series satellite data is valuable to the mapping of Arctic wetlands. Existing NWI data for the Arctic National Wildlife Refuge (ANWR) were generated using aerial photographs from 1977 to 1982 at the scale of 1:63,000 and field data collected between 1980 and 1987 [9]. Climate change, development pressure, changing methodologies in wetland mapping, and a need for higher resolution and contemporary information necessitate an update of NWI data in the ANWR.

Wetlands have been mapped and studied using different remote sensing data [10], including aerial photographs [11], satellite images [12], radio detection and ranging (radar) data [13], light detection and ranging (LiDAR) data [14], or combinations of these datasets $[15,16]$. Dabrowska-Zielinska et al. [17] used ALOS PALSAR and ENVISAT MERIS data to classify wetland vegetation habitats and found that microwave and optical images gave the repetitive spatial information about vegetation growth, which could be used for wetland ecosystem monitoring. Jahncke et al. [18] mapped wetlands through classifying a combination of RADARSAT-2, LiDAR, and QuickBird data using random forest algorithms and demonstrated the value of incorporating new data sources into wetland mapping. Landsat satellite data have a $30 \mathrm{~m}$ spatial resolution, a revisit period of 16 days, and a multidecadal archive [19]. They have been widely used in wetland mapping [20], and long-term trend analysis [21,22]. In our previous studies, Huang et al. [23] used high-resolution LiDAR intensity data to train a regression tree algorithm and then estimated the wetland sub-pixel water fraction (SWF) using Landsat data. Instead of using LiDAR intensity to produce training data, DeVries et al. [24] used Landsat-derived Dynamic Surface Water Extent (DSWE) data to train the random forest algorithm [25] and estimated the wetland SWF from Landsat images. The recently launched Sentinel-1 (S1) and Sentinel-2 (S2) are radar and optical satellites, respectively, with a spatial resolution of $10 \mathrm{~m}$ and a revisit time of 3-5 days at the equator [26,27]. Compared with Landsat and other satellites, S1 and S2 have a shorter revisit time and a higher spatial resolution, which provides more images and finer spatial detail for wetland characterization and mapping. Some studies have shown 
the suitability of S1 and S2 data for assisting in wetland mapping [28,29]. However, these two satellites are relatively new (launched in 2014 and 2015) and their potentials in wetland characterization need to be explored and evaluated broadly, especially in the Arctic tundra, where studies have been limited. Thus, we modified our previous approach to use Sentinel data for SWF estimation and vegetation type classification in Arctic wetlands.

This study aims to explore the synergistic use of S1 and S2 data, a digital elevation model (DEM), random forest regression and classifier, and ground field photos for characterizing Arctic wetland inundation and vegetation dynamics. In particular, the objectives are: (1) to develop a semi-automatic workflow using S2 data and random forest regression to estimate the wetland SWF and characterize wetland water regimes; (2) to classify wetland vegetation types using $\mathrm{S} 1$ and $\mathrm{S} 2$ data, water regimes, and a random forest classifier; (3) to explore the potential of using S1 and S2 data for Arctic wetland characterization.

\section{Study Area}

The study area is covered by three S2 tiles (06WWC, 06WXC, and 07WDT) and encompasses the Coastal Plain of the ANWR, which includes the "1002 Area" (Figure 1). This region is above $69^{\circ} \mathrm{N}$ and has a short ice-free season (Figure 1e). The entire study area covers $\sim 18,000 \mathrm{~km}^{2}$. The southern region of the study area is mountainous, with elevation ranging from 400 to $2700 \mathrm{~m}$ and slopes ranging from 10 degrees to 75 degrees. The northern region is a flat region and features many lakes and ponds distributed throughout. Several rivers and streams originate in the southern mountainous region and flow north to the Arctic Ocean. Many of the largest rivers are braided, and thus the riverbeds are wide, and water typically only covers parts of the river channels. With the exception of the highest elevations in the alpine and barren river bars, most of the study area is covered by Arctic tundra vegetation. The major vegetation cover types are scrub-shrub (SS), emergent and scrub-shrub mix (EM/SS), and emergent (EM). The study area experiences a long winter and only four months (June, July, August, and September) with average temperatures above $0{ }^{\circ} \mathrm{C}$ (Figure 1e). Most precipitation also occurs during these four months, with August as the wettest month.

The Coastal Plain of the ANWR has abundant wildlife, with 35 species of land and marine mammals and over 100 species of birds identified [30]. It also serves as a breeding ground for the porcupine caribou, an important area for denning polar bears, a habitat for muskoxen, and a gathering place for migrating waterfowl [30]. The ANWR Coastal Plain is rich in petroleum, with 10 major petroleum plays (groups of nearby oil fields or prospects) identified and a total estimated volume of 11.6-31.5 billion barrels of oil [31,32]. The 1002 Area is being prepared for oil drilling [33], which would likely involve substantial infrastructure development, including the construction of several airstrips and well pads, 175 miles of roads and a pipeline network, and a barge landing and storage site [34]. Oil development is anticipated to affect the environment [35], wildlife [36], and indigenous peoples [33]. 



Figure 1. Coastal Plain of the Arctic National Wildlife Refuge (ANWR) study area: (a) location of study area, ANWR, and weather station, (b) S2 images, (c) digital elevation model (DEM), (d) slope, (e) monthly average temperature and precipitation of weather station at Barter Island Long Range Radar Service Airport (see Figure 1a).

\section{Materials and Methods}

\subsection{Data}

S2 Level-1C products and S1 Level-1 Ground Range Detected (GRD) High Resolution (HR) products were downloaded from the Copernicus Open Access Hub (https:/ / scihub. copernicus.eu/dhus accessed on 6 October 2020) to local servers using a Python API nested in the sentinelsat software. We did not download S2 Level-2A products because they were not available for the entire study period. We only downloaded data during the ice-free season (June, July, August, and September) of 2016-2019. We downloaded 171 S1 images, with a total size of $\sim 150$ gigabytes. We also downloaded 915 S2 images, with a total size of $\sim 400$ gigabytes. Digital elevation models (DEMs) at $5 \mathrm{~m}$ resolution were downloaded from the U.S. Geological Survey (USGS) 3D Elevation Program (3DEP) using the National Map Data Download and Visualization Services [37]. Monthly precipitation and monthly temperature data were downloaded from the weather station at Barter Island Long Range Radar Service Airport [38].

\subsection{Preprocessing}

S2 Level-1C products are in $100 \times 100 \mathrm{~km}$ tiles. They are ortho-images in UTM/WGS84 projection, and their pixel values are radiometric measurements of top-of-atmosphere (TOA) reflectance. S2 TOA data were converted into S2 surface reflectance (SR) data using the L2A_Process module in Sen2Cor software [39]. The 20-m S2 bands were resampled to $10 \mathrm{~m}$. The study region has heavy cloud coverage. A considerable amount of cloud and cloud shadow was not removed by the scene classification layer. Thus, out of the 915 S2 images downloaded, 139 with relatively low cloud coverage were manually selected for use. We manually delineated a cloud and cloud shadow mask for each of the 139 S2 images (Figure 2). The mask and the scene classification layer were used together to remove snow, 
cloud, and cloud shadow. The sun's zenith angle and azimuth angle were used along with a DEM to simulate and remove terrain shadows. Remaining pixels were used for SWF estimation.

S1 Level-1 Ground Range Detected (GRD) products are focused SAR data projected to ground range using an Earth ellipsoid model. The S1 data were processed using the S1 Toolbox in SNAP [40]. The processes used included Apply-Orbit-File, Calibration, and Terrain-Correction. For use with S2 data in wetland detection, S1 images were re-projected into the UTM/WGS84 projection and subset into $100 \times 100 \mathrm{~km}$ tiles.

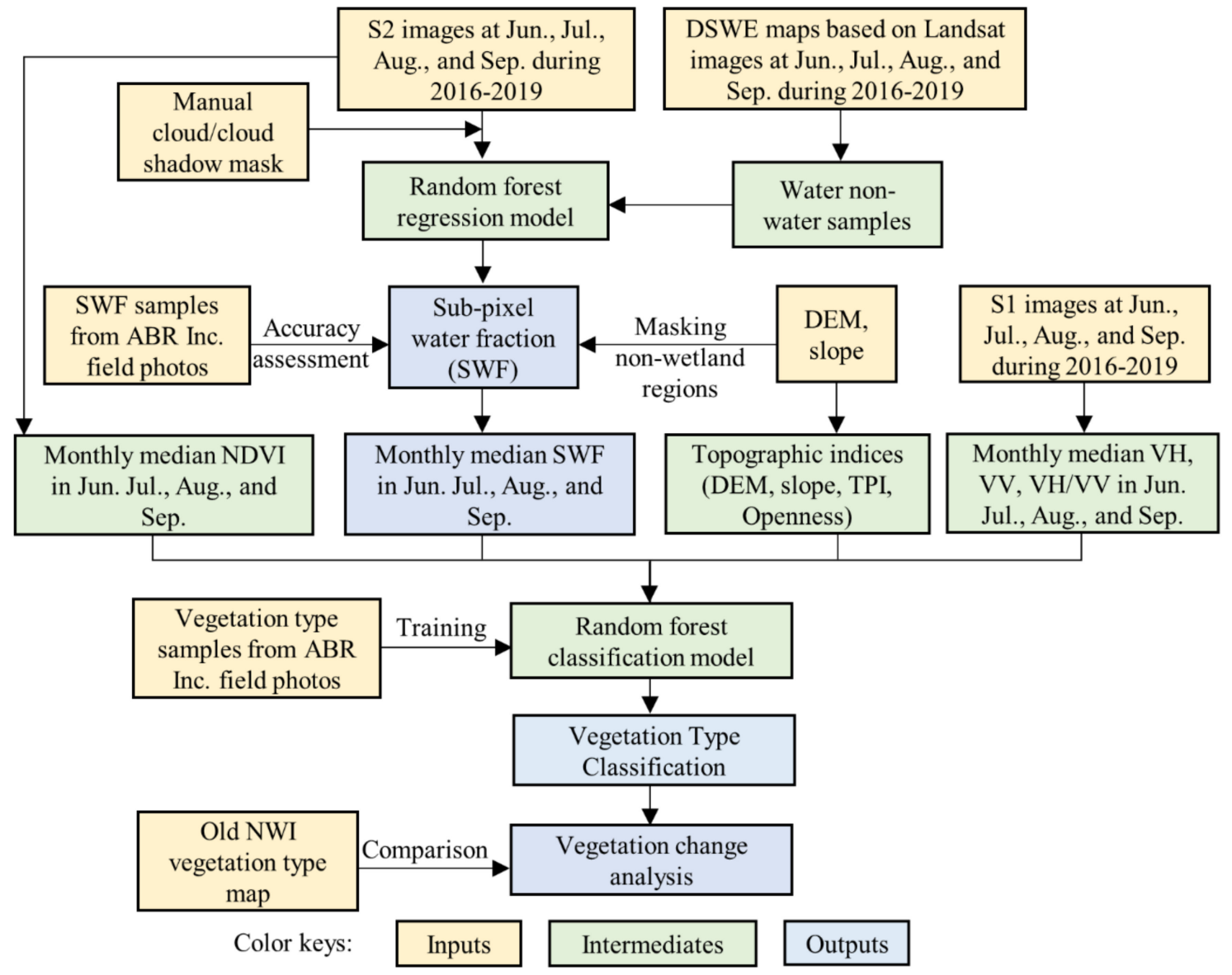

Figure 2. Overview of study product development workflow.

\subsection{Sub-Pixel Water Fraction}

We generated time series sub-pixel water fraction (SWF) maps using a slight modification of the automated algorithm described in DeVries et al. (2017). First, a Dynamic Surface Water Extent (DSWE) product map was generated using every available Landsat 7 and 8 image in the Google Earth Engine (GEE) [41]. Frequencies of open water classes and non-water classes were computed using the corresponding classes in all DSWE maps. Using data from 2016-2019's growing seasons, regions with high open water frequency were defined as water mask, while regions with high non-water frequency were defined as non-water mask. The water and non-water masks were resampled from 30 to $10 \mathrm{~m}$ spatial resolution to allow overlay with S2 images. SWF values ranging from $0 \%$ to $100 \%$ were generated using water and non-water masks. For example, for an SWF value of $55 \%, 55$ water pixels and 45 non-water pixels were randomly selected from the water and non-water masks, respectively. Radiometric measurements of the corresponding 100 pixels from the S2 SR image were averaged to simulate a mixed pixel with an SWF value of $55 \%$. The Normalized Difference Vegetation Index (NDVI) and Modified Normalized Difference Water Index (mNDWI) were computed from the bands of simulated pixels. This process 
was repeated 100,000 times for each of the 139 selected S2 images. The combined simulated bands and indices were used as independent variables, while the SWF values of these pixels were used as dependent variables in a random forest regression model [24]. Finally, the model was applied to the entire S2 image to detect the SWF at $10 \mathrm{~m}$ spatial resolution.

The median value of SWF maps within a month was extracted to form a gap-free monthly composite map. Monthly composites of the SWF were only generated for the ice-free months of June, July, August, and September, using the median value of all SWF values within the same month from 2016 to 2019. Some residual snow still exists in June and this region is so cloudy that some areas have no cloud-free images in August, which will lead to small gaps in June and August monthly composites. Thus, we adjusted the range of each month to include more images in June and August so as to avoid those gaps. After adjustment, the number of images used to generate each monthly composite is: 52 for June, 24 for July, 46 for August, and 17 for September. The 20th, 50th, and 80th percentiles of all SWF maps were also generated to represent low, medium, and high inundation levels. They can be used to analyze the magnitude of inundation dynamics across time. A DEM was used to mask mountain tops with perennial ice cover $(>1000 \mathrm{~m})$ and steep slopes ( $>10$ degrees) as non-wetland. The SWF values of non-wetland regions were set to zero.

\subsection{Reference Data and Accuracy Assessment}

About four thousand field photos were collected by ABR, Inc., Fairbanks/Anchorage, AK, USA, Environmental Research and Services from 300 sampling plots across the study area in late July and early August 2019. An aerial survey team took photos of the landscape at each plot from a helicopter. Photos of the ground were taken after the helicopter landed. While on the ground, the aerial survey team recorded data on vegetation structure and foliar cover of the dominant plant species. A ground team recorded detailed information on plant species composition, the general environment, and soil stratigraphy.

For the purposes of this study, samples for training and validation were delineated based on these field photos and Esri/Maxar high-resolution images (DigitalGlobe Vivid mosaic/Maxar) (Figure 3). Sample polygons were manually delineated in regions with relatively homogeneous land covers, each polygon covering 10 S2 pixels. The SWF value was visually estimated with a step of 5\% (e.g., $0,5 \%, 10 \% \ldots 100 \%$ ) based on field photos and satellite images. Vegetation types were also visually estimated according to field photos. Differences in collection time between field photos and S2 images were mostly a few days, with a maximum of 14 days. In total, 313 polygons were manually drawn (Figure 3), covering $738510 \times 10 \mathrm{~m}$ pixels. 

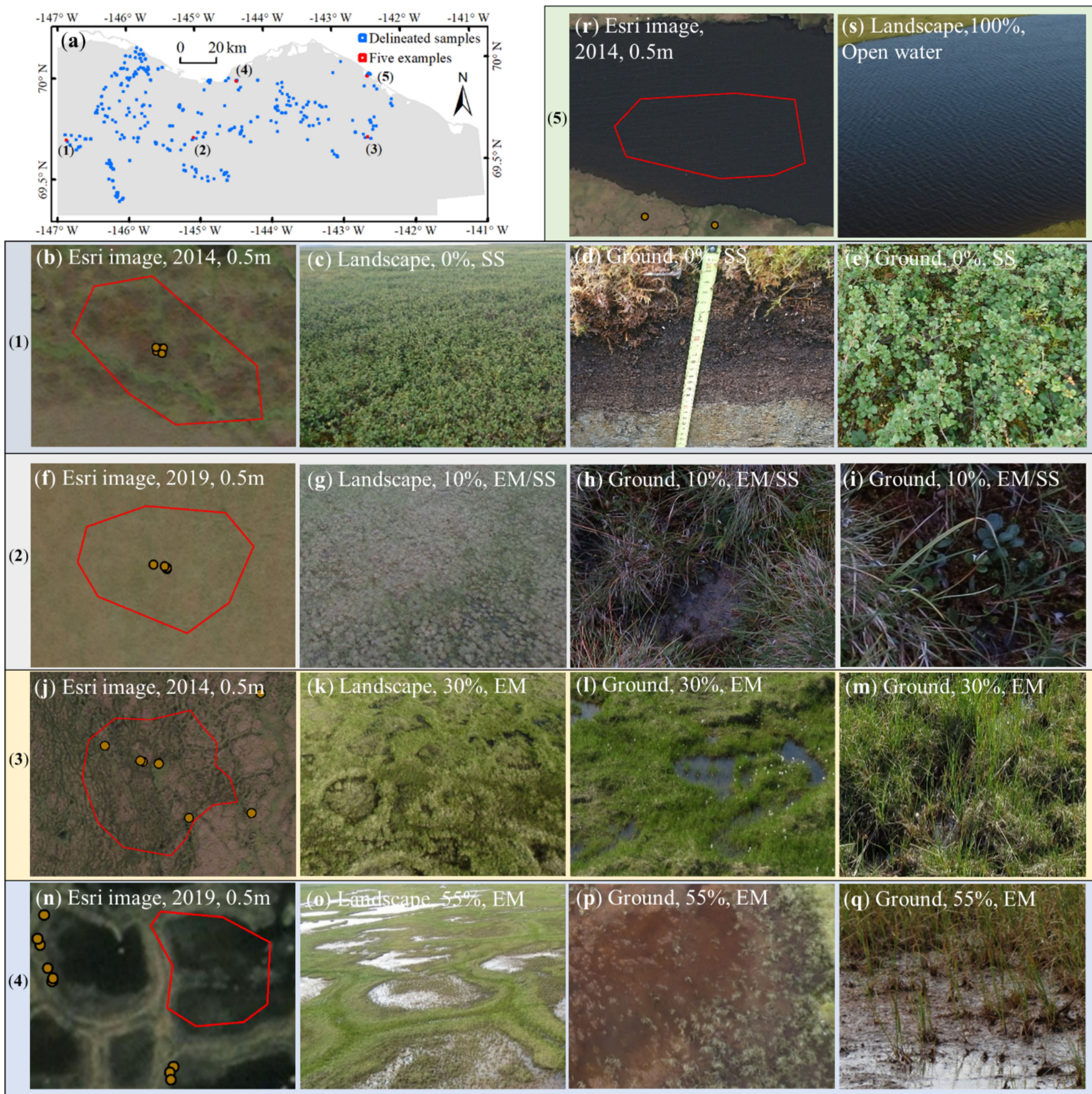

Figure 3. Delineated polygons with reference sub-pixel water fraction (SWF) value and vegetation type based on field photos (provided by ABR, Inc., Fairbanks/Anchorage, AK, USA) taken from the ground (3rd (d,h,l,p) and 4th columns $(\mathbf{e}, \mathbf{i}, \mathbf{m}, \mathbf{q}))$ and helicopters (2nd column $(\mathbf{c}, \mathbf{g}, \mathbf{k}, \mathbf{o}, \mathbf{s}))$ as well as available Esri/Maxar high-resolution images (1st column $(\mathbf{b}, \mathbf{f}, \mathbf{j}, \mathbf{n}, \mathbf{r})$ ) over 5 example locations (rows 2-5 and right side of first row). The Esri/Maxar image column shows the location of available field photos (golden circles) and the delineated polygons (red) as well as the resolution and acquisition date of the images used. SWF value and vegetation type determined for each location are shown in the other three columns. A total of 313 reference polygons were delineated across the north slope of the Arctic National Wildlife Refuge (ANWR) region (a).

\subsection{Vegetation Type Classification}

For the purpose of NWI mapping, vegetation types and associated land covers (hereafter referred to as vegetation type) in the ANWR were divided into 7 classes [8]: scrubshrub (SS), emergent (EM), emergent and scrub-shrub mix (EM/SS), scrub-shrub and barren (SS/barren) mix, emergent and barren (EM/Barren) mix, open water, and barren 
(Table 1). The vegetation and associated land covers were defined using Cowardin et al., 1979 [42].

Table 1. Vegetation types and associated land covers.

\begin{tabular}{cc}
\hline Codes & Vegetation Types and Associate Land Covers \\
\hline SS & Scrub-shrub, at least $70 \%$ areal coverage \\
\hline EM & Emergent, at least $70 \%$ areal coverage \\
\hline EM/SS & Emergent and scrub-shrub mix, each class has 30-70\% areal coverage \\
\hline SS/Barren & Scrub-shrub and barren mix, each class has 30-70\% areal coverage \\
\hline EM/Barren & Emergent and barren mix, each class has 30-70\% areal coverage \\
\hline Open water & Water, at least $70 \%$ areal coverage \\
\hline Barren & Regions without vegetation or water, rock/sand/clay/glacier, at least $70 \%$ areal coverage \\
\hline
\end{tabular}

To evaluate the performance of the random forest algorithm in vegetation type classification, we randomly selected $70 \%$ of the 313 sample polygons to train the random forest classification model, applied the model to generate a vegetation type map, and then used the remaining $30 \%$ of the polygons as reference data to produce a confusion matrix. We repeated this procedure three times for different randomizations and combined the three confusion matrixes. The predictor variables of our random forest classification model included monthly median SWF, monthly median NDVI, monthly median S1 VH polarization and S1 VV polarization, and the ratio VH/VV of June, July, August, and September. Topographic indices were also used as predictor variables, including DEM, slope, openness index, and three topographic position indices with radiuses of 3, 30, and 300 pixels. All of the 313 samples were used to train the random forest classification model used to generate a vegetation type classification with seven classes. The vegetation types from old NWI maps, derived using images and field investigation data during the 1980s, were also classified into seven classes (Table 1). To examine the possible changes in vegetation types over the last three decades, the new classification was compared with the old NWI vegetation maps.

\subsection{SWF Compared with Old NWI Water Regimes}

The old NWI polygons did not match well with new satellite images (Figure 4). One reason for this geospatial mismatch could be the relatively poor geospatial accuracy of aerial photographs used for wetland interpretation from three decades ago. For instance, the original NWI maps were produced as hard copies. Thus, the digitization of these hard copies could be another reason for their geospatial mismatch with new satellite images. To circumvent this, samples were manually delineated within the old NWI polygons to study the relationships between the SWF and NWI water regimes. The delineation avoids the regions with geospatial mismatch. It also avoids the regions with obvious land cover changes, such as the changes between vegetated and non-vegetated surfaces, expansion or shrinkage of lakes and ponds, and the movement of river channels. In this way, new polygons could retain the old NWI vegetation and water regime codes. In total, 2750 wetland samples were manually delineated at random locations across the study area (Figure 4). 

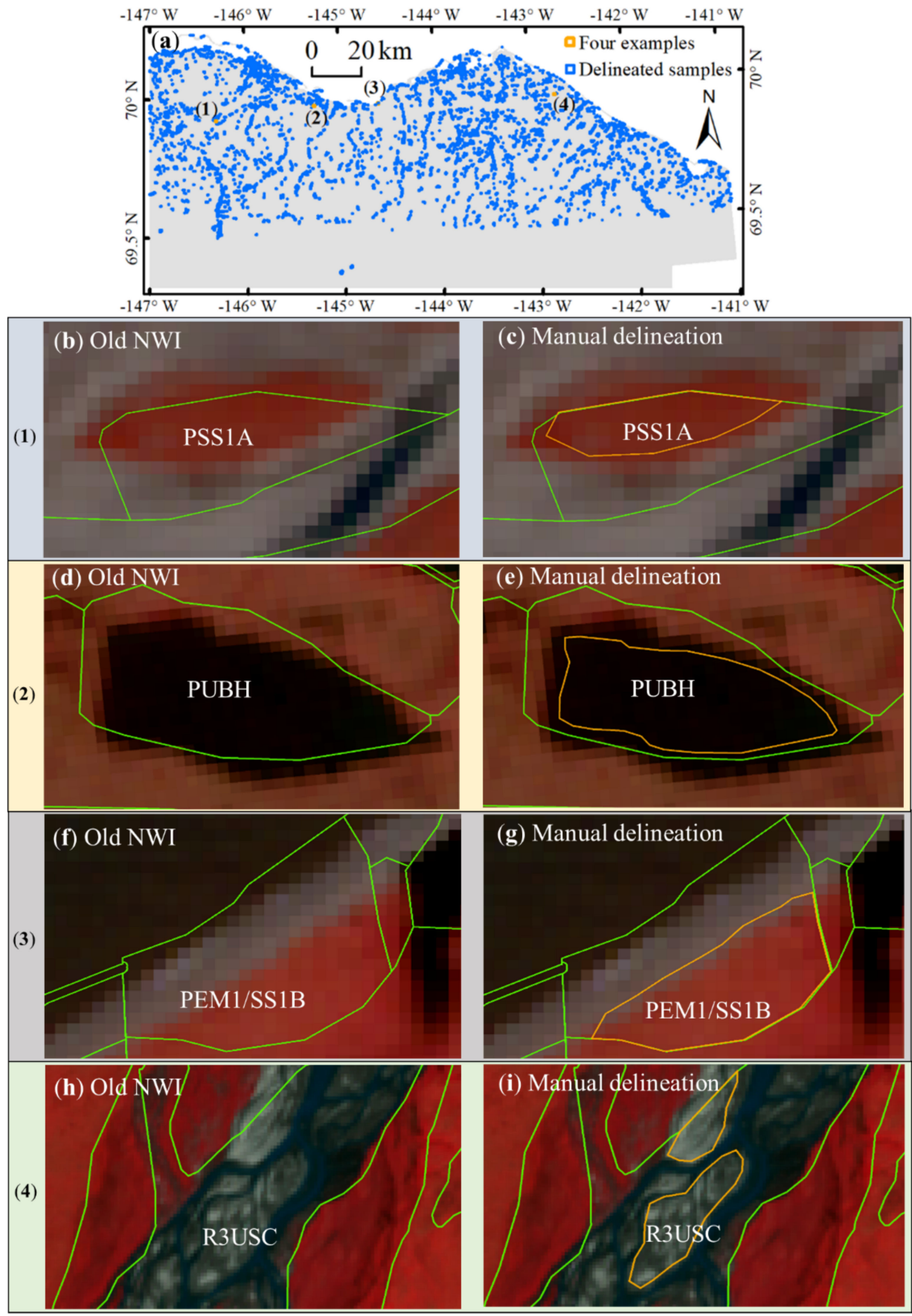

Figure 4. Sample delineation using the old National Wetlands Inventory (NWI) data in reference to 10-m S2 satellite images. Samples delineated and locations of four example areas (a). Example areas illustrated using a 2019 S-2 image overlaid with the old NWI data (green) and manually delineated polygons (orange; $\mathbf{b}-\mathbf{i}$ ), including areas with: (1) scrub-shrub vegetation and temporarily flooded water regime, (2) unconsolidated bottom land cover and permanently flooded water regime, (3) mixture of emergent and scrub-shrub vegetation and seasonally saturated water regime, and (4) unconsolidated shore and seasonally flooded water regime. A total of 2750 wetland polygons were delineated across the Coastal Plain of the ANWR (a).

In an effort to explore the relationships between NWI water regimes and SWF maps generated in this study, we used each NWI water regime as a mask to extract SWF values from the 50th percentile map. Then, we analyzed the distribution of SWF values within each water regime class (Table 2). 
Table 2. Water regime codes and their full names [42].

\begin{tabular}{cccccc}
\hline & Nontidal & & Saltwater Tidal & & Freshwater Tidal \\
\hline Code & Name & Code & Name & Code & Name \\
A & Temporarily Flooded & L & Subtidal & Q & Regularly Flooded-Fresh Tidal \\
B & Seasonally Saturated & M & Irregularly Exposed & R & Seasonally Flooded-Fresh Tidal \\
C & Seasonally Flooded & N & Regularly Flooded & S & Temporarily Flooded-Fresh Tidal \\
D & Continuously Saturated & P & Irregularly Flooded & T & Semipermanently Flooded-Fresh Tidal \\
E & Seasonally Flooded/Saturated & & & V & Permanently Flooded-Fresh Tidal \\
F & Semipermanently Flooded & & & \\
G & Intermittently Exposed & & & \\
H & Permanently Flooded & & & \\
J & Intermittently Flooded & & & \\
K & Artificially Flooded & & & \\
\hline
\end{tabular}

In an effort to seek the dominant inundation situations across ice-free seasons, four monthly SWF composites (June, July, August, and September) were used to classify inundation levels. Each monthly composite was divided into inundation levels: open water $(75 \%<$ SWF $\leq 100 \%)$, high-level inundation $(50 \%<$ SWF $\leq 75 \%)$, medium-level inundation $(25 \%<$ SWF $\leq 50 \%)$, low-level inundation $(3 \%<\mathrm{SWF} \leq 25 \%)$, and not detected $(\mathrm{SWF} \leq 3 \%)$. For each pixel, the class that appears most frequently over the four monthly composites was set as the final inundation level.

\section{Results}

\subsection{SWF and Inundation Dynamics}

\subsubsection{SWF Product Validation}

The majority of model-estimated SWF data corresponded well with the field-based reference data (Figure 5). Most boxes are distributed near the 1-to-1 line. Although the sample polygons were delineated in relatively homogeneous regions, heterogeneity may still exist, leading to some pixels with smaller or larger water coverage values relative to the average. Overall, $93 \%$ of the 5788 detected SWF values were within a $\pm 10 \%$ difference of the reference SWF values.

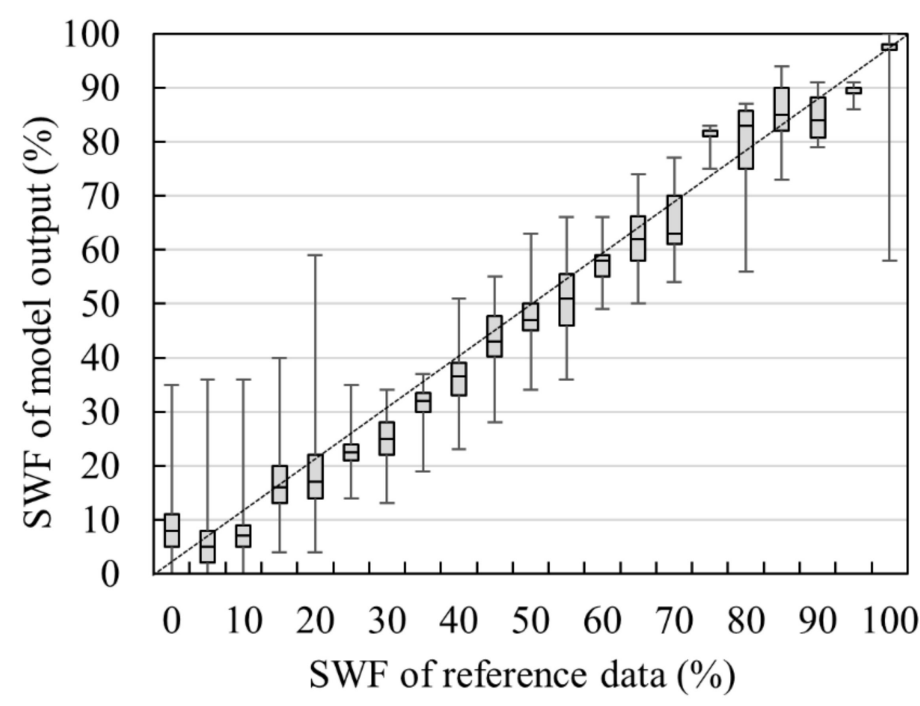

Figure 5. Box plots of mapped SWF values for pixels within reference data polygons of different SWF levels show that the median of map values tracks the reference data along the 1:1 line. Each shaded box represents the range between upper and lower 25 percentiles from the median (indicated by the horizontal bar inside the box) of mapped SWF values for a given reference SWF level, and the maximum and minimum of those values are represented by the upper and lower ends of the two vertical lines extending from the box. 
Different levels of surface water inundation in a small topographic depression are captured by the SWF map (Figure 6a,b). Ponds with open water are blue in the SWF map, with SWF values of $\sim 100$. Surrounding the ponds, the central green region is covered by a mixture of water and vegetation, with SWF values of $50-80 \%$. The golden edges of the depression have SWF values of $20-40 \%$, while the orange region outside the depression has SWF values of $<20 \%$. These SWF inundation gradients were also reflected by the field photo (Figure 6c).
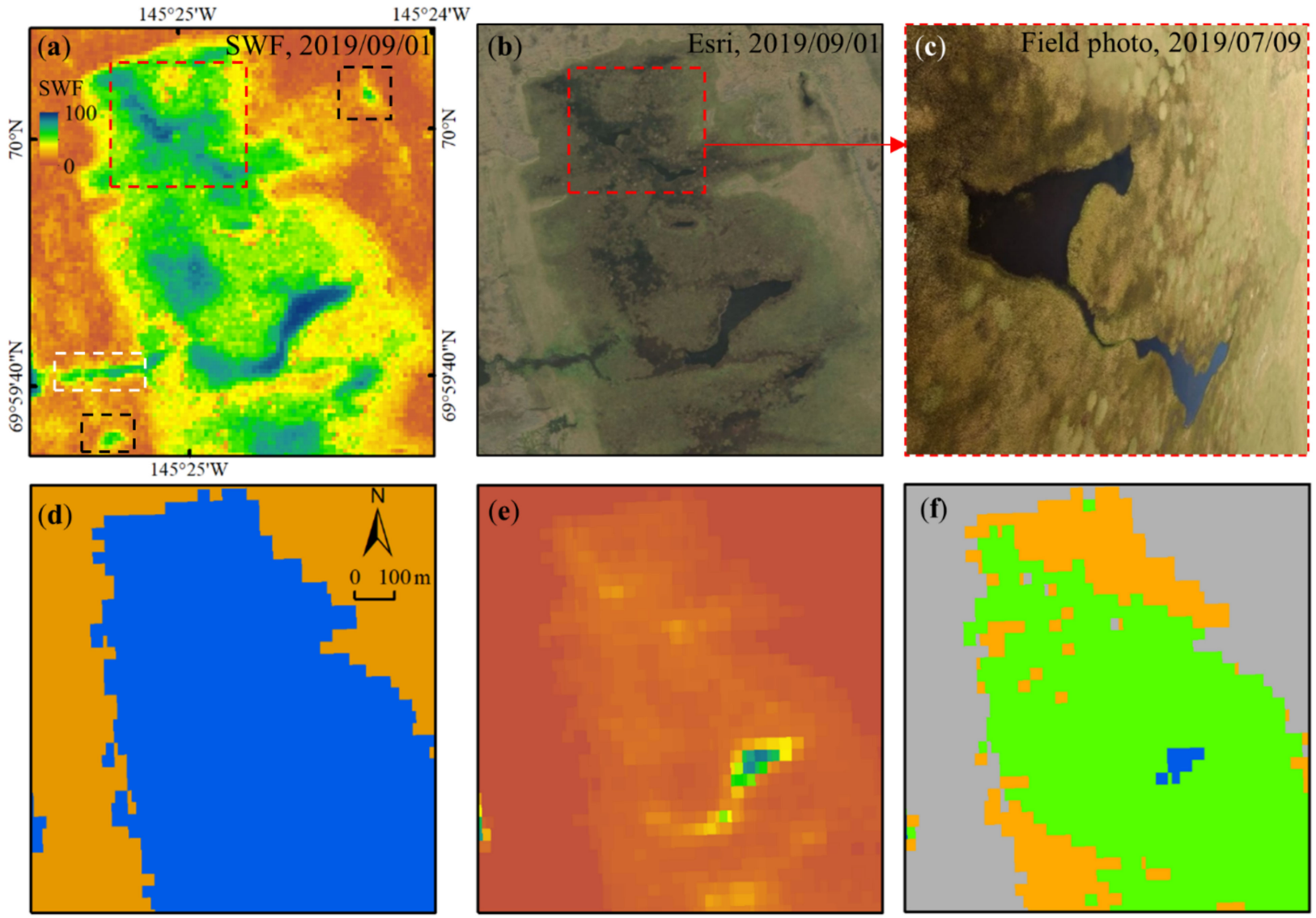

JRC max water extent
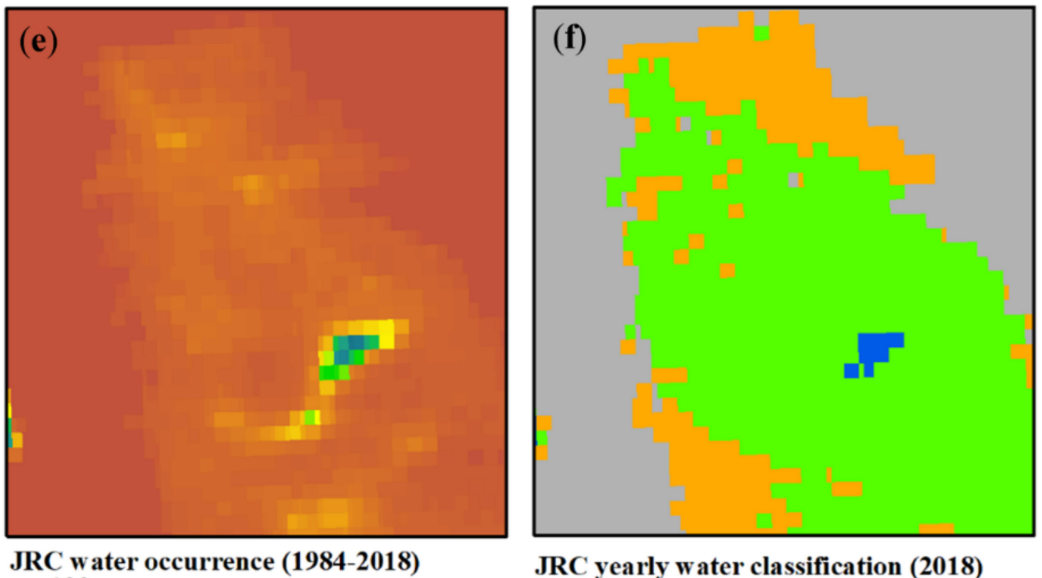

$\square$ Non-water Water

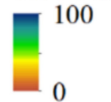

JRC yearly w ater classification (2018)

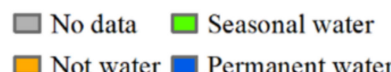

Figure 6. SWF map compared with Esri/Maxar high-resolution image, field photo, and European Joint Research Center (JRC) water body maps: (a) SWF map on 1 September 2019 shows moisture gradients from open waterbodies to partially inundated areas to dry land, (b) Esri/Maxar high-resolution image on 1 September 2019, (c) field photo of the red box region on 1 July 2019, (d) JRC maximum water extent map, (e) JRC water occurrence map, (f) JRC yearly water classification map of 2018. The dashed red squares in $(\mathbf{a}, \mathbf{b})$ indicate the zoomed-in region of $(\mathbf{c})$. Two dashed black squares and one dashed white square in (a) indicate the water features captured by the SWF map but missed by JRC products.

Compared to the SWF map in this study, the widely used European Joint Research Center (JRC) products, including the maximum water extent map (Figure 6d), water occurrence map (Figure 6e), and yearly water classification map (Figure 6f), capture less detail. Two small ponds (black boxes) and a short water channel (white box) shown in the SWF map were not captured by the JRC products. The JRC water occurrence map (Figure 6e) is less sensitive in representing wetland inundation gradients. The JRC yearly water classification map (Figure 6f) has coarser boundaries for different water classes and only parts of the permanent water class are captured in this map. These differences were partly caused by the lower spatial resolution of JRC products $(30 \mathrm{~m})$ compared to the SWF map $(10 \mathrm{~m})$. Another reason lies in the mixed pixels of water and land. The JRC's algorithm 
classifies them into water or non-water while our algorithm estimates their sub-pixel water fractions. In general, our SWF map captures more wetland inundation area, shows more detail in the gradients of wetland inundation, and provides finer wetland boundaries.

\subsubsection{Seasonal Dynamics}

The monthly median SWF composite for June provides inundation information of the entire study area (Figure 7), $90 \%$ of which has an SWF of $<25 \%, 3 \%$ has an SWF from $25 \%$ to $50 \%, 1 \%$ has an SWF from $50 \%$ to $75 \%$, and $6 \%$ has an SWF of $\geq 75 \%$ (Table 3). Lakes, ponds, rivers, and streams across the region were all well captured. SWF composites in June, July, August, and September reveal surface inundation seasonal dynamics (Figure 7b-f). Inundation was highest in June, at $1134 \mathrm{~km}^{2}$, and lowest in July, with $1054 \mathrm{~km}^{2}$. August and September were intermediate, with $1100 \mathrm{~km}^{2}$ and $1094 \mathrm{~km}^{2}$ of inundation, respectively (Table 3). In the rectangular topographic depression region, SWF values peaked in June, decreased greatly in July, increased slightly in August, and then decreased again in September. The patterns of seasonal dynamics match the statistics in Table 3. The higher-level inundation in June was likely due to the melting of accumulated snow over the previous winter, as June is the first month with an average temperature above $0{ }^{\circ} \mathrm{C}$. When the meltwater drains or evaporates in July, the inundation level decreases dramatically. August has the highest monthly precipitation (Figure 1e), which could explain why inundation increases in this month.
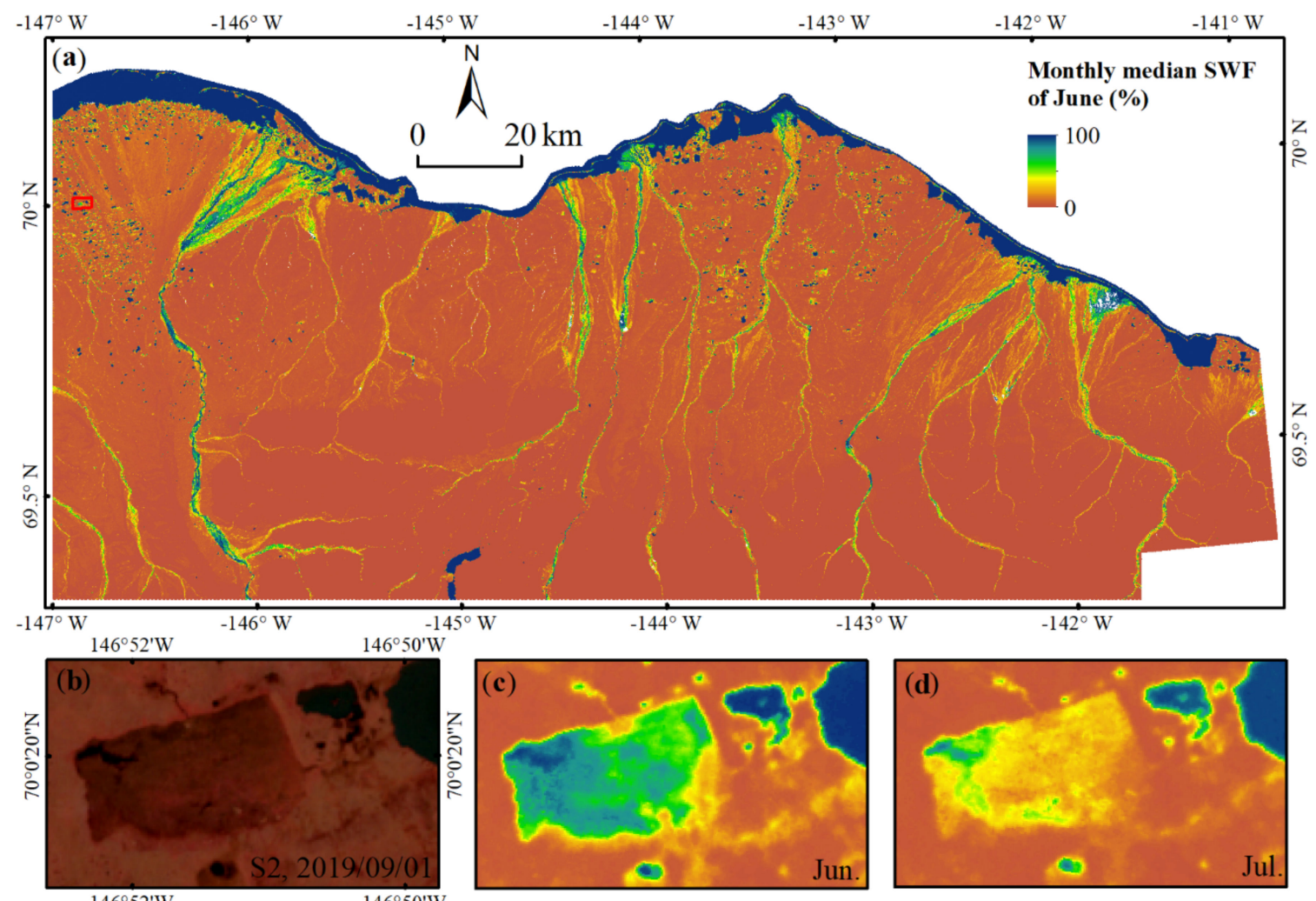

$146^{\circ} 52^{\prime} \mathrm{W}$

$146^{\circ} 50^{\prime} \mathrm{W}$
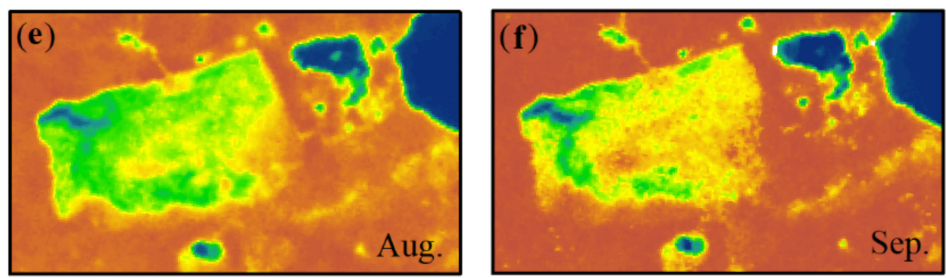

Figure 7. SWF monthly composite and seasonal dynamics: (a) SWF monthly composite of June, (b) S2 image of the zoomed-in region of (a) shown in red rectangle, (c-f) SWF monthly composite of June, July, August, and September of the zoomed-in region. 
Table 3. Area of different SWF intervals for June, July, August, and September in the Coastal Plain of the ANWR.

\begin{tabular}{cccccc}
\hline \multicolumn{5}{c}{ Area at Different SWF Intervals $\mathbf{( k m}^{\mathbf{2}} \mathbf{l}$} \\
\hline June & {$[0,25)$} & {$[25,50)$} & {$[50,75)$} & {$[75,100)$} & sum \\
July & 17,034 & 558 & 268 & 1134 & 18,994 \\
August & 17,258 & 472 & 209 & 1054 & 18,994 \\
September & 16,959 & 645 & 291 & 1100 & 18,994 \\
\hline
\end{tabular}

\subsubsection{Locations and Magnitudes of Change}

Different inundation levels were captured by the 20th, 50th, and 80th percentile SWF maps. The difference between the 80th and 20th percentile maps highlights inundation change location and magnitude (Figure 8). Inundation levels in some vegetated wetlands increased gradually from the 20th percentile SWF map to the 50th, and then to the 80th percentile SWF maps (Figure 8). In comparison, some lakes and ponds with open surface water have relatively stable inundation $(\sim 100 \%)$ across different percentile maps. Similarly, dry uplands also have stable inundation of $\sim 0 \%$. Obvious changes mostly happen at riverbeds, the edges of lakes and ponds, and wetlands in topographic depressions, where water levels change substantially between dry and wet seasons. Some vegetated wetlands have an SWF change of $\sim 50 \%$, while most lakes and ponds have an SWF change of $10 \%-30 \%$ at their edges (Figure $8 \mathrm{f}$ ). Between the 80th and 20th percentile SWF maps, $89.2 \%$ $\left(16,980 \mathrm{~km}^{2}\right)$ of the study area has an SWF variation of $<10 \%, 8.5 \%\left(1621 \mathrm{~km}^{2}\right)$ has an SWF variation between $10 \%$ and $25 \%, 2.1 \%\left(394 \mathrm{~km}^{2}\right)$ has an SWF variation between $25 \%$ and $50 \%$, and $0.2 \%\left(42 \mathrm{~km}^{2}\right)$ has a variation of $\geq 50 \%$ (Figure $8 \mathrm{a}$ ).

\subsubsection{Linking SWF to NWI Water Regimes}

The permanently or continuously flooded water regimes, including $\mathrm{H}, \mathrm{L}$, and $\mathrm{V}$, exhibited high SWF values in the 50th percentile map (Figure 9). Specifically, 98.7\%, 99.3\%, and $99.8 \%$ of the $\mathrm{H}, \mathrm{L}$, and $\mathrm{V}$ water regimes, respectively, were covered by pixels with SWF $\geq 90 \%$. The regularly flooded water regimes $\mathrm{N}$ and $\mathrm{Q}$ had $46.9 \%$ and $63.6 \%$ of pixels with SWF $\geq 90 \%$, respectively, followed by $27.0 \%$ and $13.1 \%$ of pixels with SWF between $80 \%$ and $90 \%$, respectively. Temporarily flooded (A) and seasonally flooded/saturated (E) water regimes also had low SWF values, with $55.0 \%$ and $75.8 \%$ of their corresponding regions covered by pixels with SWF $<10 \%$, followed by $26.3 \%$ and $16.0 \%$ of regions covered by pixels with SWF between $10 \%$ and $20 \%$, respectively. Areas with a seasonally saturated water regime (B) had the lowest SWF values, with $93.6 \%$ covered by pixels with an SWF of $<10 \%$. In general, water regimes characterized by frequent inundations by definitions had high SWF values, while water regimes with infrequent inundations by definitions had low SWF values. 

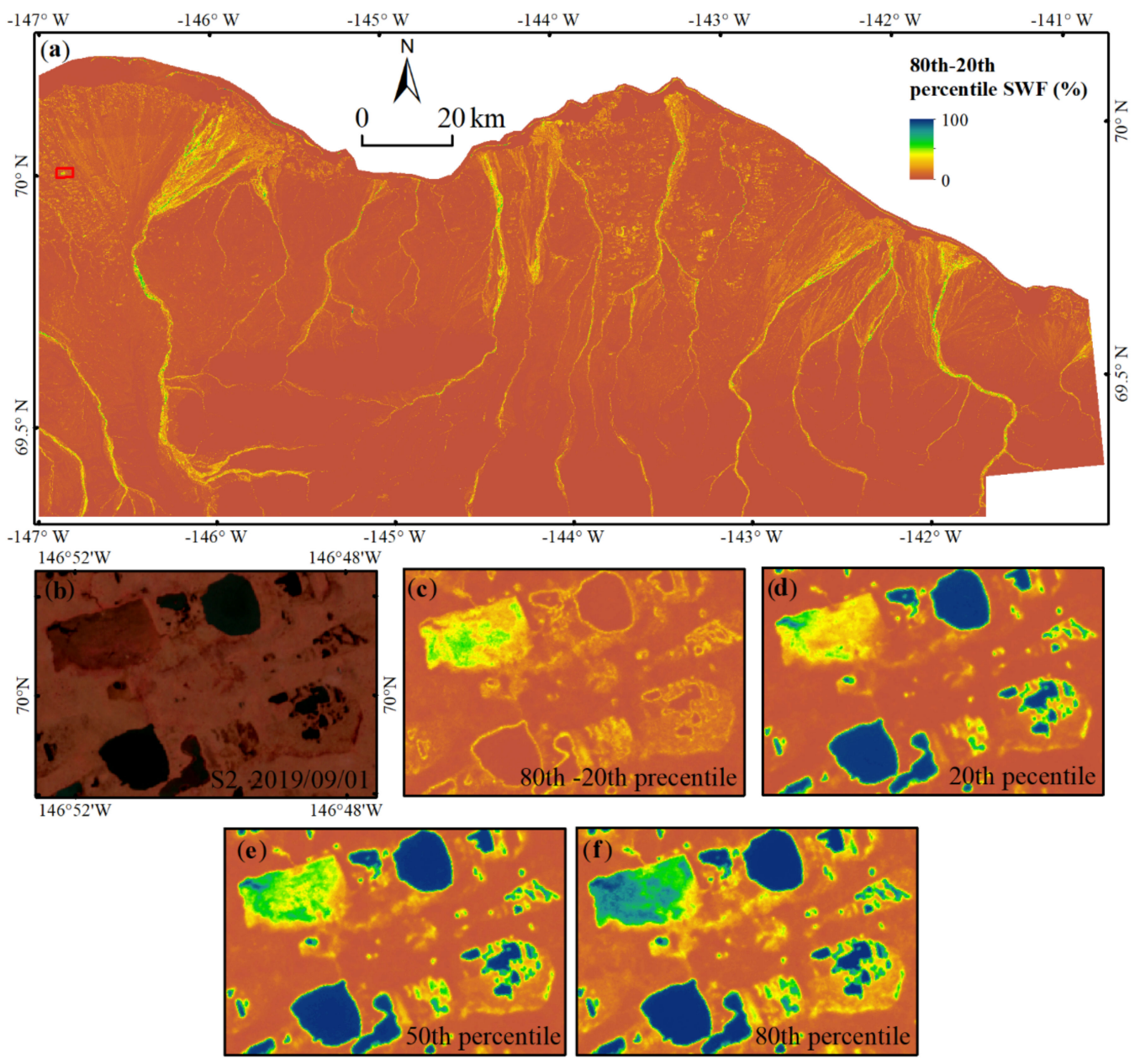

Figure 8. SWF percentile maps: (a) difference map between 80th and 20th percentile maps, (b) S2 image of the zoomed-in region of (a) shown in red rectangle, (c) difference map of the zoomed-in region, (d-f) 20th, 50th, and 80th percentile SWF maps of the zoomed-in region.

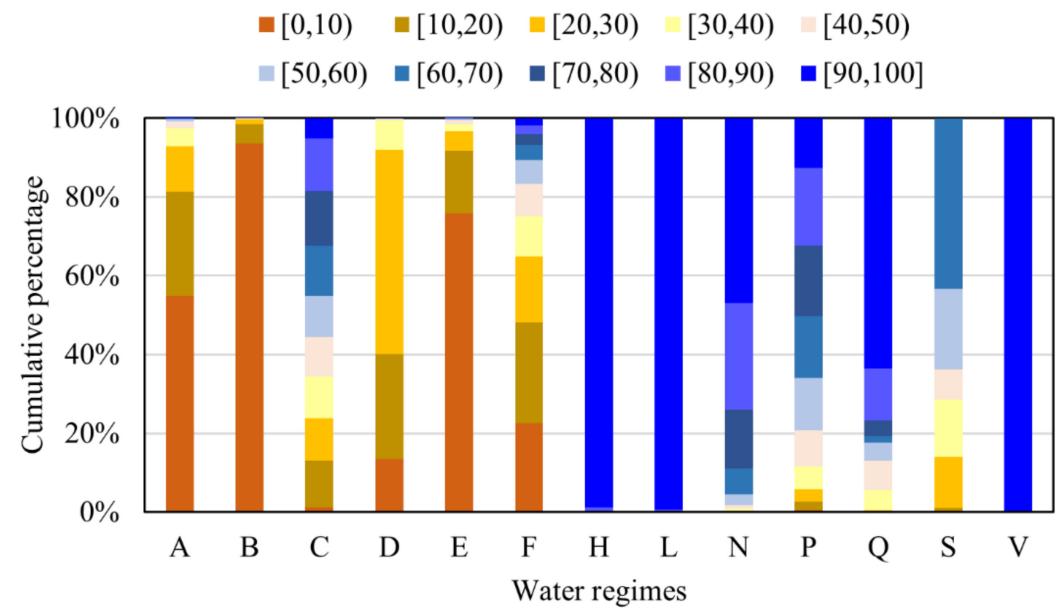

Figure 9. SWF distribution across different water regimes [42]. A: Temporarily flooded, B: Seasonally saturated, C: Seasonally flooded, D: Continuously saturated, E: Seasonally flooded/saturated, F: Semipermanently flooded, H: Permanently flooded, L: Subtidal, N: Regularly flooded, P: Irregularly flooded, Q: Regularly flooded-fresh tidal, S: Temporarily flooded-fresh tidal, V: Permanently floodedfresh tidal. A total of 2750 old NWI wetland polygons were used.

Inundation levels, derived from four monthly composites, are shown in Figure 10. Within the study site, $8130 \mathrm{~km}^{2}$ of the area was not detected (SWF $\leq 3 \%$ ), $8930 \mathrm{~km}^{2}$ exhibited 
low-level inundation/saturation ( $3 \%<\mathrm{SWF} \leq 25 \%), 580 \mathrm{~km}^{2}$ exhibited medium-level inundation $(25 \%<\mathrm{SWF} \leq 50 \%), 320 \mathrm{~km}^{2}$ exhibited high-level inundation $(50 \%<\mathrm{SWF} \leq 75 \%)$, and $1070 \mathrm{~km}^{2}$ exhibited open water (SWF $>75 \%$ ). In unchanged regions, such as a permanently flooded lake (Figure 10b), the inundation level classification map can be a good indicator of the water regimes in the old NWI polygon (Figure 10c). In changed regions, such as a partly inundated topographic depression, identified as permanently flooded with an unconsolidated bottom in the old NWI several decades ago (wetland code: L1UBH, Figure 10d), the classification map can better reflect different inundation levels nowadays (Figure 10e).
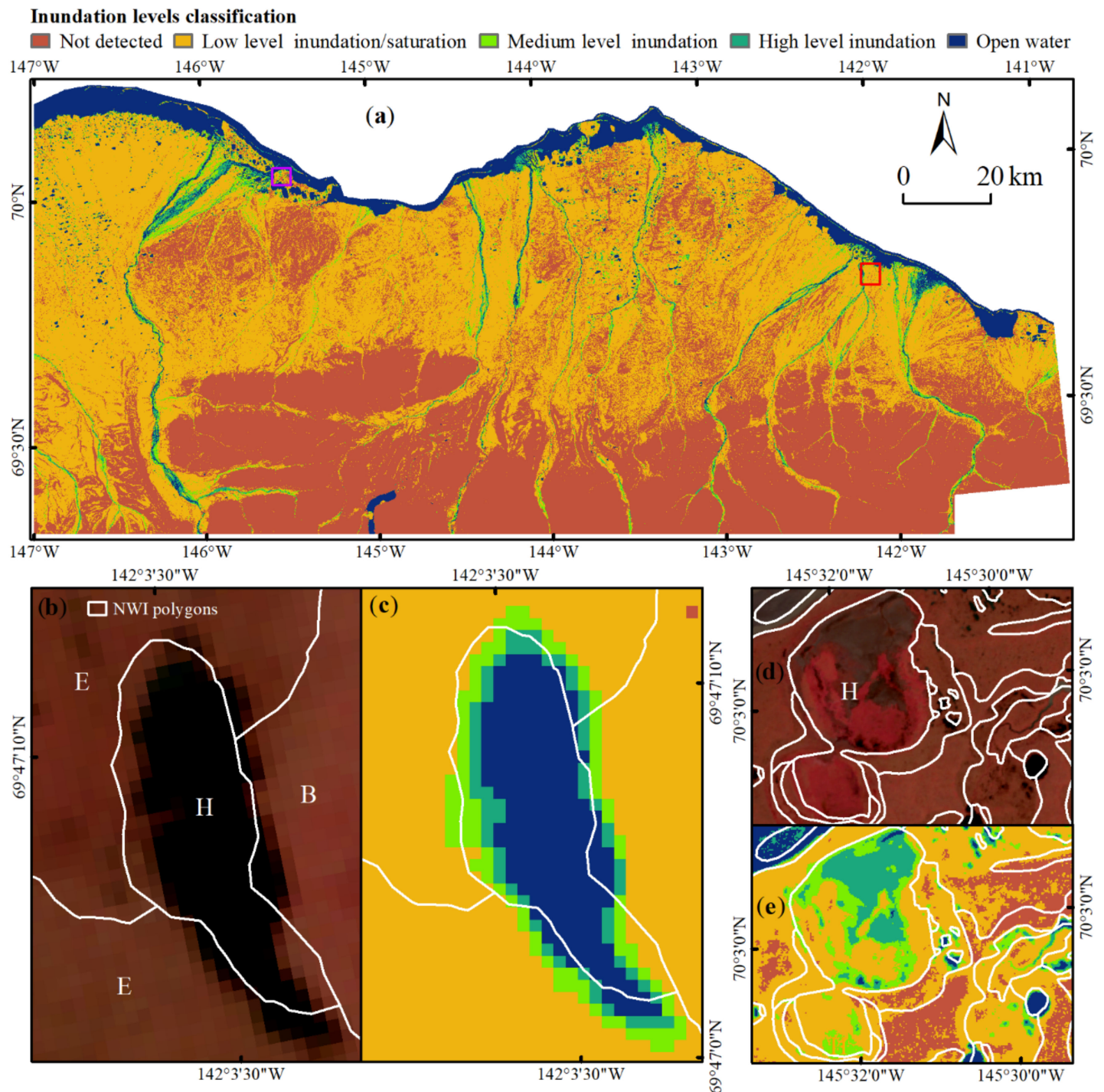

Figure 10. Water regimes maps: (a) water regimes map, (b) NWI polygons and S2 of the zoomed-in region of (a) shown in red rectangle, (c) water regimes map of zoomed-in region, (d) NWI polygons and S2 of the zoomed-in region of (a) shown in purple rectangle, (e) water regimes map of zoomed-in region. NWI water regime codes, B: Seasonally saturated, E: Seasonally flooded/saturated, H: Permanently flooded.

\subsection{Vegetation Classification and Change Analysis \\ 4.2.1. Algorithm Performance}

The random forest classification algorithm performed well when classifying vegetation types according to the combined confusion matrix table from randomization with three repeats (Table 4). The overall accuracy (OA) of all classes was 0.87 , with relatively high producer and user accuracies for most classes, especially for SS and open water. 
Table 4. Confusion matrix of algorithm performance in vegetation type classification ( $70 \%$ of the 313 sample polygons were used to train the algorithm while $30 \%$ were used as reference data to generate the confusion matrix (repeated three times for different randomizations)).

\begin{tabular}{cccccccccc}
\hline & SS & $\begin{array}{c}\text { EM/ } \\
\text { SS }\end{array}$ & EM & $\begin{array}{c}\text { SS/ } \\
\text { Barren }\end{array}$ & $\begin{array}{c}\text { EM/ } \\
\text { Barren }\end{array}$ & $\begin{array}{c}\text { Open } \\
\text { Water }\end{array}$ & Barren & Sum \\
Accuracy
\end{tabular}

\subsubsection{Vegetation Classification Map}

The vegetation type classification map is illustrated in Figure 11. For the entire study area, the emergent and scrub-shrub mix is the dominant vegetation type $\left(12,018 \mathrm{~km}^{2}\right)$, followed by barren $\left(2867 \mathrm{~km}^{2}\right)$, emergent $\left(1431 \mathrm{~km}^{2}\right)$, open water $\left(1211 \mathrm{~km}^{2}\right)$, scrub-shrub and barren mix $\left(680 \mathrm{~km}^{2}\right)$, scrub-shrub $\left(622 \mathrm{~km}^{2}\right)$, and, finally, emergent and barren mix $\left(197 \mathrm{~km}^{2}\right)$. Most of the scrub-shrub land cover was distributed along riverbanks and the foot of mountains, while most of the emergent land cover was distributed in the coastal delta regions and at the edges of lakes. The emergent and scrub-shrub mix was found between scrub-shrub and emergent. Barren land cover was commonly found on mountain tops, steep slopes, and riverbanks.

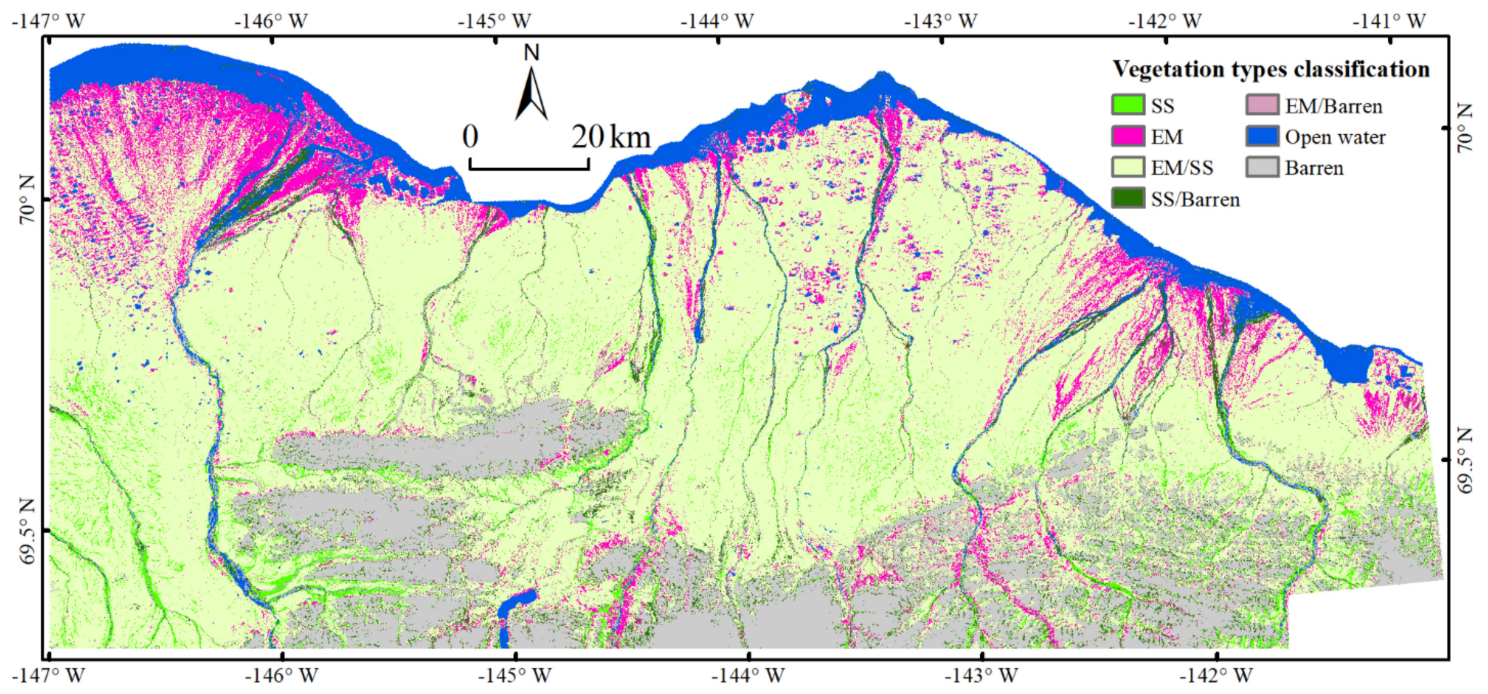

Figure 11. Vegetation type classification map (10 m spatial resolution, generated by random forest algorithm trained using all 313 sample polygons).

\subsubsection{Vegetation Change}

To avoid the influence of geospatial mismatch, the area of each vegetation class in the new classification was summed up and compared with the classifications from the old NWI maps (Table 5). Between the old NWI (1970s /1980s) and new classification (2016-2019), EM had the greatest areal decrease $\left(-521 \mathrm{~km}^{2}\right)$, while EM/SS had the greatest areal increase $\left(264 \mathrm{~km}^{2}\right)$. In terms of percentage change, SS showed the largest increase $(182 \%)$, while barren experienced the largest decrease $(-69 \%)$ (Table 5). Areas that exhibited an increase in shrub vegetation were closely examined, again, using field photos and the dominance of shrubs was confirmed (Figure 12). 
Table 5. Areal comparison of vegetation types between old NWI and new classification within the Coastal Plain of the ANWR study area.

\begin{tabular}{ccccc}
\hline & Old NWI $\left.\mathbf{( k m}^{\mathbf{2}}\right)$ & New Classification $\left.\mathbf{( k m}^{\mathbf{2}}\right)$ & Areal Change $\left.\mathbf{( k m}^{\mathbf{2}}\right)$ & Areal Change Percentage \\
\hline SS & 91 & 258 & 166 & $182 \%$ \\
EM/SS & 8824 & 9088 & 264 & $3 \%$ \\
EM & 1688 & 1167 & -521 & $-31 \%$ \\
SS/Barren & 86 & 232 & 146 & $170 \%$ \\
EM/Barren & 51 & 116 & 65 & $127 \%$ \\
Open water & 996 & 1146 & 150 & $15 \%$ \\
Barren & 390 & 119 & -271 & $-69 \%$ \\
Sum & 12,126 & 12,126 & & \\
\hline
\end{tabular}

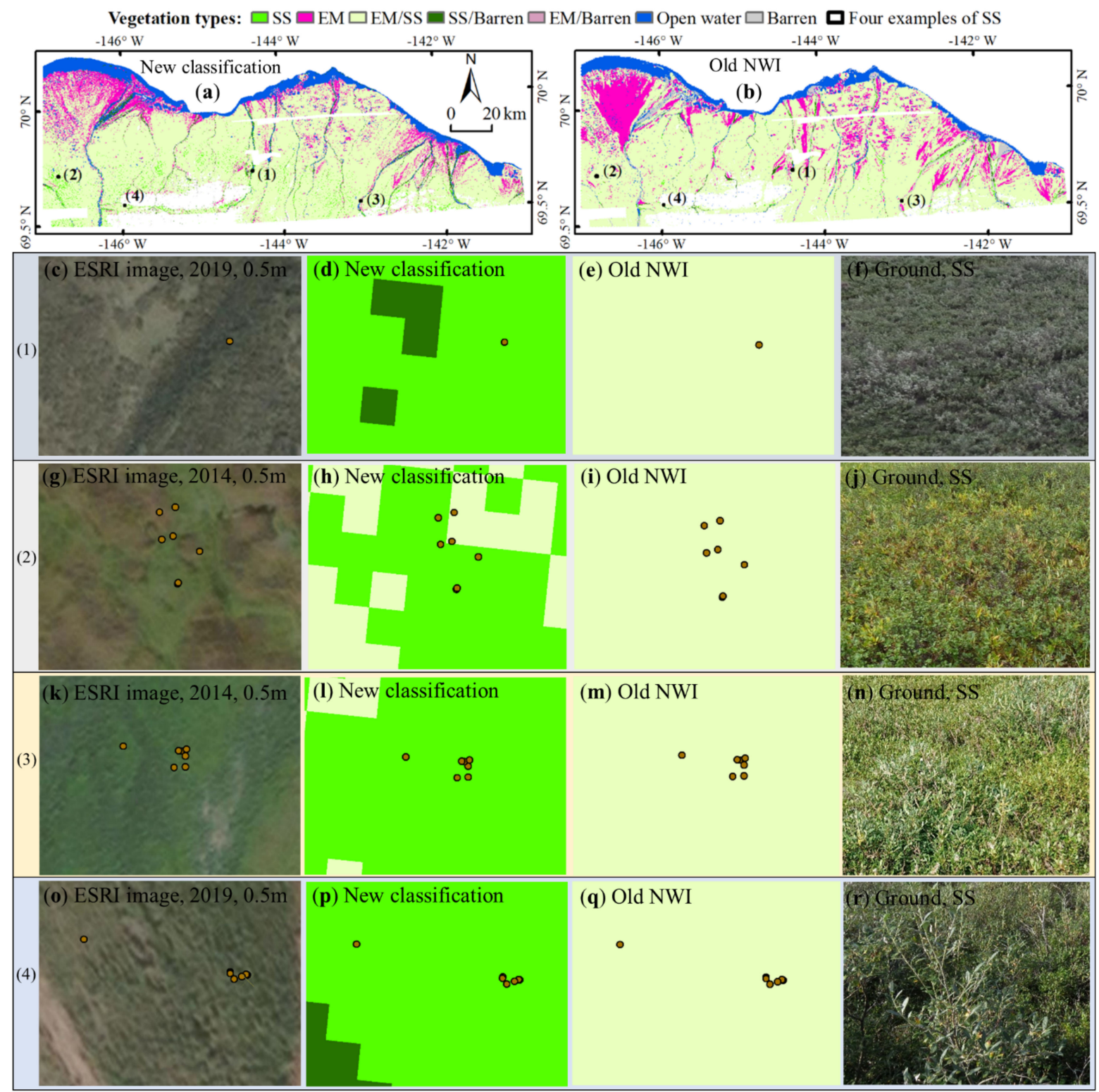

Figure 12. Vegetation type comparison between the new classification and old NWI over four example locations (1-4). The first column shows an Esri/Maxar high-resolution image with image acquisition date and spatial resolution as well as the location of available field photos $(\mathbf{c}, \mathbf{g}, \mathbf{k}, \mathbf{o})$. The second column is the new classification $(\mathbf{d}, \mathbf{h}, \mathbf{l}, \mathbf{p})$, while the third column is old NWI vegetation type $(\mathbf{e}, \mathbf{i}, \mathbf{m}, \mathbf{q})$. The fourth column shows the ground field photos and vegetation type determined for each location $(\mathbf{f}, \mathbf{j}, \mathbf{n}, \mathbf{r})$. The four examples marked in (a) and (b) are shown in rows (1-4). 


\section{Discussion}

\subsection{Surface Water Regimes}

Along with global warming, studies have found changes in water regimes across Arctic Alaska [5]. For example, tundra inundation is observed to be decreasing and runoff is increasing due to ice-wedge degradation and changes in snow distribution [43]. The formation of new beaver ponds was also observed in the Arctic tundra due to the expansion of beaver colonization in a warming climate [44]. SWF products and their monthly and percentile composites in this study show good relationships with water regimes of wetlands. Thus, they can help to better understand hydrologic dynamics and near-term trends within the Arctic.

Although the random forest regression algorithm performed well in estimating the SWF, it exhibited relatively lower accuracy in regions with SWF $\leq 10 \%$. This may partly be due to the available reference data. Most of the ANWR lacks roads and has very limited hydrological stations or other monitoring networks. Field surveys in Arctic regions are costly due to the need to travel by helicopter to access locations without roads. Arctic field surveys also face challenges from the short ice-free season, extreme weather, and persistent fog banks at the coast stretching miles inland. Thus, there are very limited ground observation data available for use as reference data. The field photos collected by ABR, Inc., Fairbanks/Anchorage, AK, USA-Environmental Research and Services are the best ground observation data we could find for SWF product validation. The accuracy of visual estimation of the SWF from field photos and Esri/Maxar high-resolution satellite images could be affected by several aspects, including clear view of the ground, accurate delineation of homogeneous regions with the same SWF, and alignment issues between S2 and Esri/Maxar high-resolution images. In order to capture a larger area, many field photos were not taken perpendicularly to the ground, which leads to the partial obstruction of surface water by vegetation in the photo.

The detail of surface water regimes was also affected by the limited availability of highquality S2 images. The S2 scene classification layer could not be used to efficiently remove cloud and cloud shadows, which leads to commission and omission errors. Unfortunately, the study region is very cloudy, reducing the number of high-quality images. Thus, surface water regimes are not able to reflect the short-term changes in surface water coverage, such as flash flooding. In this study, we need to improve the S2 scene classification layer with manual interpretation of cloud and cloud shadow masks, which makes the approach less efficient. New algorithms were developed recently to improve the scene classification layer, such as machine learning [45] and random forest classifiers [46]. We will adopt these new algorithms and avoid manual interpretation of cloud masks in future studies, which will make our approach more efficient.

\subsection{Vegetation Type Classification}

The vegetation type classification demonstrated relatively high accuracies for the SS, EM/SS, and EM classes, which is likely due to the high-quality training and validation samples. Compared with surface water, vegetation has a much larger areal coverage within the ANWR, enabling the selection of high-quality samples from field photos. Vegetation type can be clearly identified using ground field photos, while the extent of such vegetation can be determined using landscape field photos and Esri/Maxar high-resolution images. Compared to EM and EM/SS, SS has obvious texture on Esri/Maxar high-resolution images, making it easier to delineate. Field photos taken on the ground are key to identification of vegetation type and areal coverage due to the presence of many dwarf shrubs, which are difficult to identify even from the photos taken from a helicopter. Thus, high-quality field sampling data are critical in the training of advanced classification algorithms. The vegetation type map in this study is not an NWI or wetlands map. An NWI wetland map considers water regimes, vegetation types, water chemistry, expertise, etc., and classifies wetland types based on the Cowardin wetland classification [42]. For example, the class of Barren here can be divided into upland barren, riverine barren, and barren on tidal flats in 
NWI wetland maps. This study focuses on S1 and S2 data. However, it is worth to mention that other radar data, such as ALOS PALSAR and RADARSAT1/2, may assist in Arctic wetland vegetation classification.

\subsection{Potential Vegetation Type Changes}

Previous studies have shown changes in vegetation types in Arctic Alaska $\left(>65^{\circ} \mathrm{N}\right)$, especially the expansion of shrubs as a result of climate warming [47]. This expansion is likely to continue alongside global warming (Zhou et al., 2020). Compared with old NWI data, SS demonstrated the largest percentage increase of $182 \%\left(166 \mathrm{~km}^{2}\right)$ of any other vegetation class in the new classification. This may indicate the expansion of shrubs similar to what was found by other studies. These studies found evidence of shrub expansion (alder, willow, dwarf birch, etc.) in northern Alaska [5,48], with changes most often found on hill slopes and in valley bottoms [49]. However, shrub expansion was not uniform, and some areas exhibited no increase at all [47].

However, although our data seem to support shrub expansion, the old NWI maps were produced using relatively coarse scale analog imagery, and we were unable to validate these older data, including the shrub class. Thus, more evidence is needed to support the findings of shrub expansion in this study, specifically a long-term monitoring network to understand shrub expansion and the nature behind it. Regions that were identified as experiencing potential shrub expansion in our study may be locations where vegetation is reactive to climate change, thus they could be good locations for field-based monitoring.

\section{Conclusions}

This study developed a semi-automatic process to generate SWF maps from time series S2 satellite images. The SWF maps can capture hydrological features with relatively fine $(10 \mathrm{~m})$ spatial detail, while monthly and percentile SWF composites can reveal temporal dynamics of surface inundation. June demonstrated maximum inundation, while the least inundation was recorded in July. Riverbeds, edges of lakes and ponds, and wetlands in topographic depressions were more hydrologically dynamic, while pond centers were more stable. Areas that were classified by NWI geospatial data as having wetter and longer water regimes had higher SWF values, while those that were classified as having drier and/or shorter water regimes had relatively low SWF values. This indicates that SWF maps should be valuable for determining NWI water regimes in unmapped areas, or for updating NWI geospatial data in areas of land cover change. With field photos as training data, a random forest classifier showed good performance in classifying vegetation type. The derived vegetation information also has substantial value in the generation of new NWI geospatial data or updating of existing NWI data since NWI's classification system depends heavily on both vegetation type and water regime. The automated nature of SWF map production and its dependence on freely available input data make the use of this approach for applications, including wetland mapping, cost-effective and therefore more feasible. This study demonstrates the great potential of S1 and S2 data in characterizing wetland inundation and vegetation dynamics in Arctic regions. The Sentinel constellation and Landsat mission highly improved the temporal and spatial detail in wetland characterization. However, for regions under heavy cloud coverage, the radar satellite missions, such as RADARSAT1/2, TerraSAR-X, and ALOS-2, could assist in wetland mapping and monitoring, especially when more and more of these high-quality data become publicly available.

Author Contributions: Conceptualization, Z.Z., C.H. and M.W.L.; methodology, Z.Z., C.H. and B.D.; software, B.D.; validation, S.T., G.W.M., A.G.R., J.K. and L.D.; formal analysis, Z.Z., C.H. and B.D.; investigation, A.F.W., M.J.M. and A.G.R.; resources, M.W.L., S.T., G.W.M., J.K. and L.D.; writingoriginal draft preparation, Z.Z., C.H. and M.W.L. All authors have contributed to review and editing. All authors have read and agreed to the published version of the manuscript. 
Funding: This study was funded by the U.S. Fish and Wildlife Service (USFWS) under contract F18AC00973. Additional support was provided by the USDA Agricultural Research Service (58-80429-012), USDA Natural Resources Conservation Service under their Conservation Effects Assessment Project (CEAP) program, and NASA's Land Cover and Land Use Change (LCLUC) Program.

Institutional Review Board Statement: Not applicable.

Informed Consent Statement: Not applicable.

Data Availability Statement: The data generated in this study are openly available at: https://umd. box.com/s/uhwzthid0v299mkusdt8e2fgs476zu90 accessed on 6 October 2020.

Acknowledgments: We thank the European Space Agency (ESA) Copernicus program for the free access to Sentinel-1 and -2 data.

Conflicts of Interest: The authors declare no conflict of interest. The findings and conclusions in this article are those of the authors and do not necessarily represent the views of the USFWS. Use of trade, firm, or product names is for descriptive purposes only and does not imply endorsement by the U.S. Government.

\section{References}

1. Lee, S.; Dunn, R.; Young, R.; Connolly, R.; Dale, P.; Dehayr, R.; Lemckert, C.; McKinnon, S.; Powell, B.; Teasdale, P. Impact of urbanization on coastal wetland structure and function. Austral Ecol. 2006, 31, 149-163. [CrossRef]

2. Dorney, J.; Savage, R.; Tiner, R.W.; Adamus, P. Wetland and Stream Rapid Assessments: Development, Validation, and Application, 1st ed.; Academic Press: Cambridge, MA, USA, 2018; pp. 1-18.

3. Erwin, K.L. Wetlands and global climate change: The role of wetland restoration in a changing world. Wetl. Ecol. Manag. 2009, 17, 71-84. [CrossRef]

4. Vonk, J.E.; Gustafsson, Ö. Permafrost-carbon complexities. Nat. Geosci. 2013, 6, 675-676. [CrossRef]

5. Pastick, N.J.; Jorgenson, M.T.; Goetz, S.J.; Jones, B.M.; Wylie, B.K.; Minsley, B.J.; Genet, H.; Knight, J.F.; Swanson, D.K.; Jorgenson, J.C. Spatiotemporal remote sensing of ecosystem change and causation across Alaska. Glob. Chang. Biol. 2019, 25, 1171-1189. [CrossRef] [PubMed]

6. Wilen, B.O.; Bates, M.K. The US Fish and Wildlife Service's National Wetlands Inventory Project; Springer Netherlands: Dordrecht, The Netherlands, 1995; pp. 153-169.

7. Hall, J.V.; Frayer, W.; Wilen, B.O. Status of Alaska Wetlands, 1st ed.; U.S. Fish and Wildlife Service: Anchorage, AK, USA, 1994; pp. 1-33.

8. Federal Geographic Data Committee. Classification of Wetlands and Deepwater Habitats of the United States. FGDC-STD-0042013. Second Edition. Wetlands Subcommittee, 2nd ed.; Federal Geographic Data Committee and U.S. Fish and Wildlife Service: Washington, DC, USA, 2013; pp. 1-86.

9. U.S. Fish and Wildlife Service. National Wetland Inventory Notes to the User for North Slope 1:63,360 Scale Maps, 1st ed.; U.S. Fish and Wildlife Service: Anchorage, AK, USA, 1990; pp. 1-24.

10. Guo, M.; Li, J.; Sheng, C.L.; Xu, J.W.; Wu, L. A Review of Wetland Remote Sensing. Sensors 2017, 17, 777. [CrossRef] [PubMed]

11. Tiner, R.W. Use of High-Altitude Aerial-Photography for Inventorying Forested Wetlands in the United-States. For. Ecol. Manag. 1990, 33-34, 593-604. [CrossRef]

12. Kuenzer, C.; Klein, I.; Ullmann, T.; Georgiou, E.F.; Baumhauer, R.; Dech, S. Remote Sensing of River Delta Inundation: Exploiting the Potential of Coarse Spatial Resolution, Temporally-Dense MODIS Time Series. Remote Sens. 2015, 7, 8516-8542. [CrossRef]

13. Huang, W.; DeVries, B.; Huang, C.; Lang, M.; Jones, J.; Creed, I.; Carroll, M. Automated Extraction of Surface Water Extent from Sentinel-1 Data. Remote Sens. 2018, 10, 797. [CrossRef]

14. Lang, M.; McDonough, O.; McCarty, G.; Oesterling, R.; Wilen, B. Enhanced Detection of Wetland-Stream Connectivity Using LiDAR. Wetlands 2012, 32, 461-473. [CrossRef]

15. Allen, T.R.; Wang, Y.; Gore, B. Coastal wetland mapping combining multi-date SAR and LiDAR. Geocarto Int. 2013, 28, 616-631. [CrossRef]

16. Du, L.; McCarty, G.W.; Zhang, X.; Lang, M.W.; Vanderhoof, M.K.; Li, X.; Huang, C.; Lee, S.; Zou, Z. Mapping Forested Wetland Inundation in the Delmarva Peninsula, USA Using Deep Convolutional Neural Networks. Remote Sens. 2020, 12, 644. [CrossRef]

17. Dabrowska-Zielinska, K.; Budzynska, M.; Tomaszewska, M.; Bartold, M.; Gatkowska, M.; Malek, I.; Turlej, K.; Napiorkowska, M. Monitoring wetlands ecosystems using ALOS PALSAR (L-Band, HV) supplemented by optical data: A case study of Biebrza Wetlands in Northeast Poland. Remote Sens. 2014, 6, 1605-1633. [CrossRef]

18. Jahncke, R.; Leblon, B.; Bush, P.; LaRocque, A. Mapping wetlands in Nova Scotia with multi-beam RADARSAT-2 Polarimetric SAR, optical satellite imagery, and Lidar data. Int. J. Appl. Earth Obs. Geoinf. 2018, 68, 139-156. [CrossRef]

19. Wulder, M.A.; White, J.C.; Loveland, T.R.; Woodcock, C.E.; Belward, A.S.; Cohen, W.B.; Fosnight, E.A.; Shaw, J.; Masek, J.G.; Roy, D.P. The global Landsat archive: Status, consolidation, and direction. Remote Sens. Environ. 2016, 185, 271-283. [CrossRef] 
20. Fraser, R.H.; Kokelj, S.V.; Lantz, T.C.; McFarlane-Winchester, M.; Olthof, I.; Lacelle, D. Climate sensitivity of high Arctic permafrost terrain demonstrated by widespread ice-wedge thermokarst on Banks Island. Remote Sens. 2018, 10, 954. [CrossRef]

21. Wulder, M.A.; Li, Z.; Campbell, E.M.; White, J.C.; Hobart, G.; Hermosilla, T.; Coops, N.C. A national assessment of wetland status and trends for Canada's forested ecosystems using 33 years of earth observation satellite data. Remote Sens. 2018, 10, 1623. [CrossRef]

22. Zou, Z.; Xiao, X.; Dong, J.; Qin, Y.; Doughty, R.B.; Menarguez, M.A.; Zhang, G.; Wang, J. Divergent trends of open-surface water body area in the contiguous United States from 1984 to 2016. Proc. Natl. Acad. Sci. USA 2018, 115, 3810-3815. [CrossRef]

23. Huang, C.; Peng, Y.; Lang, M.; Yeo, I.-Y.; McCarty, G. Wetland Inundation Mapping and Change Monitoring Using Landsat and Airborne LiDAR Data. Remote Sens. Environ. 2014, 141, 231-242. [CrossRef]

24. DeVries, B.; Huang, C.; Lang, M.; Jones, J.; Huang, W.; Creed, I.; Carroll, M. Automated Quantification of Surface Water Inundation in Wetlands Using Optical Satellite Imagery. Remote Sens. 2017, 9, 807. [CrossRef]

25. Breiman, L. Random forests. Mach. Learn. 2001, 45, 5-32. [CrossRef]

26. Drusch, M.; Del Bello, U.; Carlier, S.; Colin, O.; Fernandez, V.; Gascon, F.; Hoersch, B.; Isola, C.; Laberinti, P.; Martimort, P.; et al. Sentinel-2: ESA's Optical High-Resolution Mission for GMES Operational Services. Remote Sens. Environ. 2012, 120, 25-36. [CrossRef]

27. Torres, R.; Snoeij, P.; Geudtner, D.; Bibby, D.; Davidson, M.; Attema, E.; Potin, P.; Rommen, B.; Floury, N.; Brown, M.; et al. GMES Sentinel-1 mission. Remote Sens. Environ. 2012, 120, 9-24. [CrossRef]

28. Chatziantoniou, A.; Petropoulos, G.P.; Psomiadis, E. Co-Orbital Sentinel 1 and 2 for LULC Mapping with Emphasis on Wetlands in a Mediterranean Setting Based on Machine Learning. Remote Sens. 2017, 9, 1259. [CrossRef]

29. Mahdianpari, M.; Salehi, B.; Mohammadimanesh, F.; Brisco, B.; Homayouni, S.; Gill, E.; DeLancey, E.R.; Bourgeau-Chavez, L. Big Data for a Big Country: The First Generation of Canadian Wetland Inventory Map at a Spatial Resolution of 10-m Using Sentinel-1 and Sentinel-2 Data on the Google Earth Engine Cloud Computing Platform. Can. J. Remote Sens. 2020, 46, 15-33. [CrossRef]

30. Montgomery, S.L. Wildlife resources and vulnerabilities summarized for 1002 area of ANWR. Oil Gas J. 2003, 101, 34-39.

31. Montgomery, S.L. Petroleum geology and resource assessment: 1002 area, Arctic National Wildlife Refuge. AAPG Bull. 2005, 89, 291-310. [CrossRef]

32. U.S. Geological Survey. The Oil and Gas Resource Potential of the Arctic National Wildlife Refuge, 1002 Area, Alaska; U.S. Geological Survey: Reston, VA, USA, 1999; pp. 1-12.

33. Zentner, E.; Kecinski, M.; Letourneau, A.; Davidson, D. Ignoring Indigenous peoples-climate change, oil development, and Indigenous rights clash in the Arctic National Wildlife Refuge. Clim. Chang. 2019, 155, 533-544. [CrossRef]

34. Mufson, S.; Eilperin, J. Trump Administration Opens Huge Reserve in Alaska to Drilling. Available online: https: / / www.washingtonpost.com/climate-environment/trump-administration-chooses-most-expansive-approach-to-oil-gasexploration-in-alaska-wildlife-refuge/2019/09/12/cfac63cc-d597-11e9-9610-fb56c5522e1c_story.html (accessed on 8 March 2021).

35. Sovacool, B.K. Environmental damage, abandoned treaties, and fossil-fuel dependence: The coming costs of oil-and-gas exploration in the "1002 Area" of the Arctic National Wildlife Refuge. Environ. Dev. Sustain. 2007, 9, 187-201. [CrossRef]

36. Parlee, B.L.; Sandlos, J.; Natcher, D.C. Undermining subsistence: Barren-ground caribou in a "tragedy of open access". Sci. Adv. 2018, 4, e1701611. [CrossRef]

37. Sugarbaker, L.; Constance, E.W.; Heidemann, H.K.; Jason, A.L.; Lucas, V.; Saghy, D.; Stoker, J.M. The 3D Elevation Program Initiative: A Call for Action, 1st ed.; U.S. Geological Survey: Reston, VA, USA, 2014; pp. 1-48.

38. Weather Spark. Averate Weather at Barter Island LRRS Airport. Available online: https://weatherspark.com/y/145098/AverageWeather-at-Barter-Island-LRRS-Airport-Alaska-United-States-Year-Round (accessed on 6 October 2020).

39. Louis, J.; Debaecker, V.; Pflug, B.; Main-Knorn, M.; Bieniarz, J.; Mueller-Wilm, U.; Cadau, E.; Gascon, F. Sentinel-2 Sen2Cor: L2A processor for users. In Proceedings of the Living Planet Symposium 2016, Prague, Czech Republic, 9-13 May 2016; Spacebooks Online: Berlin-Adlershof/Oberpfaffenhofen, Germany, 2016; pp. 1-8.

40. Zuhlke, M.; Fomferra, N.; Brockmann, C.; Peters, M.; Veci, L.; Malik, J.; Regner, P. SNAP (sentinel application platform) and the ESA sentinel 3 toolbox. ESASP 2015, 734, 21.

41. Jones, J.W. Improved Automated Detection of Subpixel-Scale Inundation-Revised Dynamic Surface Water Extent (DSWE) Partial Surface Water Tests. Remote Sens. 2019, 11, 374. [CrossRef]

42. Cowardin, L.M.; Carter, V.; Golet, F.C.; LaRoe, E.T. Classification of Wetlands and Deepwater Habitats of the United States, 1st ed.; US Department of the Interior, US Fish and Wildlife Service: Washington, DC, USA, 1979; pp. 1-104.

43. Liljedahl, A.K.; Boike, J.; Daanen, R.P.; Fedorov, A.N.; Frost, G.V.; Grosse, G.; Hinzman, L.D.; Iijma, Y.; Jorgenson, J.C.; Matveyeva, N. Pan-Arctic ice-wedge degradation in warming permafrost and its influence on tundra hydrology. Nat. Geosci. 2016, 9, 312-318. [CrossRef]

44. Tape, K.D.; Jones, B.M.; Arp, C.D.; Nitze, I.; Grosse, G. Tundra be dammed: Beaver colonization of the Arctic. Glob. Chang. Biol. 2018, 24, 4478-4488. [CrossRef]

45. Raiyani, K.; Gonçalves, T.; Rato, L.; Salgueiro, P.; Marques da Silva, J.R. Sentinel-2 Image Scene Classification: A Comparison between Sen2Cor and a Machine Learning Approach. Remote Sens. 2021, 13, 300. [CrossRef]

46. Nevavuori, P.; Lipping, T.; Narra, N.; Linna, P. Assessment of Cloud Cover in Sentinel-2 Data Using Random Forest Classifier. In Proceedings of the IGARSS 2020-2020 IEEE International Geoscience and Remote Sensing Symposium, Waikoloa, HI, USA, 26 September-2 October 2020; p. 4664. 
47. Tape, K.D.; Hallinger, M.; Welker, J.M.; Ruess, R.W. Landscape Heterogeneity of Shrub Expansion in Arctic Alaska. Ecosystems 2012, 15, 711-724. [CrossRef]

48. Zhou, J.K.; Tape, K.D.; Prugh, L.; Kofinas, G.; Carroll, G.; Kielland, K. Enhanced shrub growth in the Arctic increases habitat connectivity for browsing herbivores. Glob. Chang. Biol. 2020, 26, 3809-3820. [CrossRef]

49. Tape, K.; Sturm, M.; Racine, C. The evidence for shrub expansion in Northern Alaska and the Pan-Arctic. Glob. Chang. Biol. 2006, 12, 686-702. [CrossRef] 